University of Nebraska - Lincoln

DigitalCommons@University of Nebraska - Lincoln

2013

\title{
Chinook Salmon Foraging Patterns in a Changing Lake Michigan
}

Gregory R. Jacobs

U.S. Fish and Wildlife Service, gregory_jacobs@fws.gov

Charles P. Madenjian

U.S. Geological Survey

David B. Bunnell

U.S. Geological Survey

David M. Warner

U.S. Geological Survey

Randall M. Caramunt

Michigan Department of Natural Resources

Follow this and additional works at: https://digitalcommons.unl.edu/usgsstaffpub

Jacobs, Gregory R.; Madenjian, Charles P.; Bunnell, David B.; Warner, David M.; and Caramunt, Randall M., "Chinook Salmon Foraging Patterns in a Changing Lake Michigan" (2013). USGS Staff -- Published Research. 710.

https://digitalcommons.unl.edu/usgsstaffpub/710

This Article is brought to you for free and open access by the US Geological Survey at DigitalCommons@University of Nebraska - Lincoln. It has been accepted for inclusion in USGS Staff -- Published Research by an authorized administrator of DigitalCommons@University of Nebraska - Lincoln. 
The American Fisheries Society claims copyright for this document, but the Office of Scholarly Communications at the University of NebraskaLincoln Libraries does not concur with that claim, maintaining it is a U.S. government work. By mutual agreement, a revised text version is presented here, rather than the published PDF, in accordance with the AFS author-posting policy.

\title{
Chinook Salmon Foraging Patterns in a Changing Lake Michigan
}

\author{
Gregory R. Jacobs, ${ }^{1}$ Charles P. Madenjian, ${ }^{2}$ David B. Bunnell, ${ }^{2}$ \\ David M. Warner, ${ }^{2}$ and Randall M. Claramunt ${ }^{3}$
}

1. U.S. Fish and Wildlife Service Northeast Fishery Center, 227 Washington Avenue, Post Office Box 75, Lamar, PA 16848

2. U.S. Geological Survey, Great Lakes Science Center, 1451 Green Road, Ann Arbor, MI 48105

3. Charlevoix Fisheries Research Station, Michigan Department of Natural Resources, 96 Grant Street, Charlevoix, MI 49720

Corresponding author - G. R. Jacobs, gregory_jacobs@fws.gov

\begin{abstract}
Since Pacific salmon stocking began in Lake Michigan, managers have attempted to maintain salmon abundance at high levels within what can be sustained by available prey fishes, primarily Alewife Alosa pseudoharengus. Chinook Salmon Oncorhynchus tshawytscha are the primary apex predators in pelagic Lake Michigan and patterns in their prey selection (by species and size) may strongly influence pelagic prey fish communities in any given year. In 1994- 1996, there were larger Alewives, relatively more abundant alternative prey species, fewer Chinook Salmon, and fewer invasive species in Lake Michigan than in 2009-2010. The years 2009-2010 were instead characterized by smaller, leaner Alewives, fewer alternative prey species, higher abundance of Chinook Salmon, a firmly established nonnative benthic community, and reduced abundance of Diporeia, an important food of Lake Michigan prey fish. We characterized Chinook Salmon diets, prey species selectivity, and prey size selectivity between 1994-1996 and 2009-2010 time periods. In 1994-1996, Alewife as prey represented a smaller percentage of Chinook Salmon diets than in 2009-2010, when alewife comprised over $90 \%$ of Chinook Salmon diets, possibly due to declines in alternative prey fish populations. The size of Alewives eaten by Chinook Salmon also decreased between these two time periods. For the largest Chinook Salmon in 2009-2010, the average size of Alewife prey was nearly $50 \mathrm{~mm}$ total length shorter than in 19941996. We suggest that changes in the Lake Michigan food web, such as the decline in Diporeia, may have contributed to the relatively low abundance of large Alewives during the late 2000s by heightening the effect of predation from top predators like Chinook Salmon, which have retained a preference for Alewife and now forage with greater frequency on smaller Alewives.
\end{abstract}

Chinook Salmon Oncorhynchus tshawytscha, along with other salmonines, were introduced in Lake Michigan during the 1960s to provide a viable sport fishery and biocontrol for nuisance Alewife Alosa pseudoharengus populations (Tody and Tanner 1966). Chinook Salmon subsequently became an effective Alewife predator (Stewart and Ibarra 1991) and the focus of a popular, multibillion-dollar sport fishery. Since their introduction, population levels of Chi- nook Salmon have been maintained through stocking practices to accomplish two conflicting management goals: (1) control of Alewife abundance, and (2) maintenance of a Chinook Salmon sport fishery dependent on available Alewife forage (Jones et al. 1993). In response to these objectives, managers have attempted to maintain salmon abundance at high levels within what can be sustained by available prey fishes, primarily Alewife. 
Alewives have been the dominant prey of Chinook Salmon in the Laurentian Great Lakes since they were first introduced, though Chinook Salmon can also prey heavily on Bloater Coregonus artedi and Rainbow Smelt Osmerus mordax (Rybicki and Clapp 1996). Despite indications that native Chinook Salmon populations in the Pacific Ocean are generalist predators (Hunt et al. 1999), evidence suggests that naturalized Chinook Salmon in Lake Michigan are strongly selective for Alewife, select against Bloater and Rainbow Smelt, and fail to significantly alter foraging preference with changes in prey abundance (Stewart et al. 1981; Jude et al. 1987). Similarly, Warner et al. (2008) found strong Chinook Salmon preference for Alewife above Bloater and Rainbow Smelt, but they also found that with increasing abundance of small Alewives, age-1 Chinook Salmon exhibited increasing preference for small Alewives and decreasing preference for large Alewives. Though this relationship did not hold for older Chinook Salmon, the results from Warner et al. (2008) are suggestive of the importance of prey size to foraging preference for this species.

Recent exotic species invasions by zebra mussels Dreissena polymorpha and quagga mussels D. bugensis (hereafter referred to as dreissenids), Round Goby Neogobius melanostomus, and the spiny water flea Bythotrephes longimanus have coincided with large-scale ecosystem change in the Great Lakes, including reduced primary production and offshore nutrient transport due to filter feeding by dreissenid mussels (Hecky et al. 2004; Depew et al. 2006), declines in native zooplankton and benthic invertebrate populations (Nalepa et al. 2006; Barbiero et al. 2009), reduced growth and condition of fishes through indirect bottom-up food web interactions (Madenjian et al. 2003; Rennie et al. 2009), and reduced abundance of native fishes through direct species interactions (Lauer et al. 2004). In Lake Huron, such changes have been implicated in the recent Alewife population collapse and offshore fish community shift (Riley et al. 2008), though increasing native and naturalized salmonine predator abundance in Lake Huron (Johnson et al. 2010) suggests that the Alewife collapse was more likely the result of top-down pressure. Due to similarities in species invasions throughout the Great Lakes, changing lower trophic level community structure, and apparent bottom-up forcing, there is some indication that similar community shifts may also occur in other lakes.

In Lake Michigan, Bunnell et al. (2006) documented a shift in offshore community composition between 1999 and 2004, coinciding with reduced species richness and lake-wide biomass estimates. For typical salmonine prey fishes, there has been a decline in the abundance of Bloaters, Rainbow Smelt, and Alewives in Lake Michigan (Warner et al. 2011; Madenjian et al. 2012), as well as a decline in Alewife growth and condition (Madenjian et al. 2003; Bunnell et al. 2009), from the 1990s to the late 2000s. Such changes in pelagic prey fish populations have left Chinook Salmon with fewer prey items. Additionally, there are indications that the abundance of Chi- nook Salmon in Lake Michigan has increased, as charter boat catch rates in the late 2000s were as much as three to four times higher than those in the 1990s (Claramunt et al. 2010). Given ongoing ecosystem change in Lake Michigan, and the possibility that a Lake Huron-like pelagic community shift may occur, predator-prey interactions between salmonines and their prey in Lake Michigan may have a similarly large effect on the pelagic prey fish community.

Forage fish monitoring, bioenergetics modeling, and statistical catch-at-age models are already employed to help set stocking levels appropriate for the amount of available prey fish in Lake Michigan (Szalai et al. 2008). Accurate bioenergetics, statistical catch at age, and even ecosystem mass-balance modeling results are dependent on accurate representations of predator- prey interactions. However, high individual variation in stomach contents and the relatively high effort and expense associated with collecting an acceptable number of diet samples can be prohibitive to comprehensive, standardized, large-scale diet studies (Elliott et al. 1996). To address this necessity, we assembled lake-wide Lake Michigan Chinook Salmon diet data from fish collected from suspended-gill-net surveys conducted by Michigan Department of Natural Resources (MDNR) during the years 1994-1996 and 2009-2010, as well as from angler tournaments during 2009-2010, to quantify and compare Chinook Salmon diets, prey selectivity, and predator size versus prey size relationships over time. Given the suite of ecosystem changes that have occurred in Lake Michigan between 1994- 1996 and 2009-2010, including the establishment of a nonnative benthic community and the conspicuously low abundance of important forage species (Rainbow Smelt, Bloater, and Alewife), changes in Chinook Salmon foraging choices are expected to occur. Our goal was to quantify the response of Chinook Salmon to ecosystem change in Lake Michigan and to identify potential implications of those changes.

\section{Methods}

Over all sampling periods, stomach contents of 2,746 (1,480 nonempty) Chinook Salmon were analyzed: 1,753 (962 nonempty) stomachs from 1994 to 1996, and 993 (518 nonempty) stomachs from 2009 to 2010. All fish from 1994 to 1996 were collected from annual fishery-independent surveys using top-water and suspended gill nets conducted by the MDNR in Lake Michigan statistical districts MM-3, MM-5, MM-6, MM-7, and MM-8. During 20092010, 147 (48 nonempty) Chinook Salmon stomachs were collected from MDNR top-water gill-net surveys conducted in statistical districts MM-6 and MM-8, and 859 (476 nonempty) Chinook Salmon stomachs were also collected from angler-caught fish. Fishery-independent gillnet surveys consisted of monofilament gill nets fished on the surface and suspended in the water column following standardized sampling protocols (Schneeberger et al. 2001). In 1994-1996, gill nets were composed of alternating 30.5-m panels with mesh sizes (stretched) of 76.2-177.8 
$\mathrm{mm}$ in $12.7-\mathrm{mm}$ increments and $76.2-152.4 \mathrm{~mm}$ in $25.4-$ $\mathrm{mm}$ increments. In 2009-2010, gill nets were composed of alternating $100-\mathrm{m}$ panels of 76.2 and $88.9 \mathrm{~mm}$ stretched mesh, where six panels of each mesh size were set for a total length of 1,200 m. Sampling took place during the night with short net sets $(<5 \mathrm{~h})$ in Michigan waters of Lake Michigan during April-September in all years. During 20092010, Chinook Salmon stomachs were collected from anglers at various salmon fishing events in Michigan, Wisconsin, Indiana, and Illinois waters of Lake Michigan.

Stomachs were frozen and contents were later thawed and analyzed following protocols described by Elliott et al. (1996). We conducted a binomial regression on the presence of diet contents as a function of time period with predator total length (TL) as a covariate to test for sizeindependent differences in percentage of empty stomachs between time periods. Individual fish prey items were identified to species, weighed to the nearest $0.1 \mathrm{~g}$ wet weight, and measured to the nearest $1 \mathrm{~mm}$ TL. Total length was determined by direct measurement when possible, or else estimated from published conversion formulae for standard length or vertebral length (Elliott $e t$ al. 1996). Invertebrates in each stomach were identified to the lowest possible taxonomic level, enumerated, and weighed en masse by prey category. Diets were characterized by calculating percentage of diet items by weight $(\% W)$, percentage of diet items by number $(\% N)$, and percentage frequency of occurrence among predator diets $(\% O)$ by prey category.

We grouped samples for analysis by predator sizeclass (small: $<500 \mathrm{~mm}$, and large: $\geq 500 \mathrm{~mm}$ ) and time period (1994-1996 and 2009-2010). Comparisons of diet percentages between time periods were conducted separately for each predator size-class using pairwise $t$-tests. To test for collection method bias, angler- and surveycaught samples were compared where fishery and fishery-independent collections occurred within the same location and time period, i.e., in MM- 6 and MM-8 lake management units in the Michigan waters of Lake Michigan during 2009-2010. We tested for differences in the percentage empty stomachs between angler- and surveycaught fish using a two-sample chi-square test with a continuity correction. To test for differences in overall diet content between angler- and survey-caught fish, we conducted pairwise comparisons of total prey weight and average TL of prey within each salmon size-class. All tests were conducted at the individual Chinook Salmon level. Kernel density plots for relative length frequency were generated to compare the range and relative frequency of Alewife prey size by predator size-class and time period.

We used prey fish abundance estimates (number/ ha) from fishery-independent surveys conducted by the U.S. Geological Survey Great Lakes Science Center and the MDNR as baseline prey availability for prey selection analysis. The abundance of pelagic prey fish species (Alewife, Rainbow Smelt, and Bloater) was estimated from annual acoustic surveys conducted in the late summer-early Fall for all years in this study (Warner et al. 2011). Mid- water trawls were deployed during acoustic sampling to gather species and size composition data. Acoustic data in the 1990s were analyzed using custom software (Argyle et al. 1998), whereas the 2009-2010 data were analyzed using Echoview 4.8 software. We used a technique described by Warner et al. (2008) to assign species and size composition to acoustic data, and estimated abundance using methods described in Warner et al. (2011). Alewives were split into two size-classes: a small size-class of fish $<120 \mathrm{~mm}$ TL composed primarily of age- 0 and age- 1 Alewives, and a large size-class of fish $\geq 120 \mathrm{~mm}$ TL composed primarily of age-2 and older Alewives. The abundance of Round Gobies, a benthic species, was estimated from annual lakewide bottom trawl surveys using methods described by Madenjian et al. (2003) and Bunnell et al. (2006).

We examined prey selectivity for three major pelagic fishes (Alewife, Rainbow Smelt, and Bloater), as well as for the recent invasive Round Goby. To investigate changes in prey selection among time periods and sizeclasses, we used Chesson's index of prey selection, denoted herein by $C$ (Chesson 1978),

$$
C=\left(r_{i} / p_{i}\right) \div\left(\sum_{1}^{m} r_{i} / p_{i}\right)
$$

where $r$ is the numeric proportion of the diet item $i$ in the diet, $p$ is the numerical proportion of diet item $i$ in the environment, $m$ is the number of prey categories, and $i$ ranges from 1 to $m$. Selection values greater than $1 / m$ indicate "selection" or "preference," those less than $1 / m$ indicate avoidance, and those equal to $1 / m$ indicate neutral selection. Under this definition, predators show preference for or select prey items if they are found to have consumed them in higher proportion than their proportional availability in the environment. For both time periods, prey selection was estimated for small and large Chinook Salmon using a prey assemblage of four categories: small Alewife $(<120 \mathrm{~mm}$ TL), large Alewife $(\geq 120 \mathrm{~mm}$ TL), Rainbow Smelt, and Bloater. For 2009-2010, selectivity was also calculated using a prey assemblage that included a fifth category for Round Goby, which was absent from salmon diets and prey survey data in 1994-1996, in order to assess whether Chinook Salmon have been able to exploit this recently established prey resource.

To test for size-dependent foraging patterns of Chinook Salmon on their primary prey, Alewife, we fit continuous regressions models to mean Alewife prey length in Chinook Salmon predator stomachs across predator TL and tested for differences between time periods using indicator variables and backward stepwise regression procedures. A posteriori observation of the Alewife prey length versus Chinook Salmon predator length data suggested a nonlinear, asymptotic relationship with potentially significant differences in prey size maxima between time periods. Though simple linear regression has been used in previous studies for prey length versus predator length relationships (Jude et al. 1987), we determined a nonlinear approach was more appropriate given our 
Table 1. Pairwise tests for differences in diet contents by capture source in lake management units MM-6 and MM- 8 in the Michigan waters of Lake Michigan during 2009-2010. Total diet weight was natural logarithm ( $\log _{e}$ ) transformed prior to calculating mean and performing pairwise tests. Weights were then back-transformed for reporting. Chinook Salmon size-classes were Small $(\mathrm{TL}<500 \mathrm{~mm})$ and Large $(\mathrm{TL} \geq 500 \mathrm{~mm})$. Sample sizes $(n)$ are included in parentheses.

\begin{tabular}{|c|c|c|c|c|c|c|}
\hline Size class & Response & Angler mean $(n)$ & Survey mean $(n)$ & df & Test statistic & $P$ \\
\hline Large & Percent nonempty & $52.81 \%(178)$ & $46.43 \%(28)$ & 1 & $x^{2}=0.180$ & 0.671 \\
\hline Large & Total diet weight & $6.99 \mathrm{~g} \mathrm{(93)}$ & $6.19 \mathrm{~g} \mathrm{(13)}$ & 16.11 & $t=0.243$ & 0.811 \\
\hline Small & Mean prey TL & $114.7 \mathrm{~mm}(32)$ & $104.4 \mathrm{~mm}(23)$ & 52.94 & $t=1.4541$ & 0.152 \\
\hline Small & Mean Alewife TL & $116.1 \mathrm{~mm}(29)$ & $103.8 \mathrm{~mm}(20)$ & 46.23 & $t=1.6224$ & 0.112 \\
\hline Large & Mean Alewife TL & $137.9 \mathrm{~mm}(90)$ & $143.9 \mathrm{~mm} \mathrm{(13)}$ & 19.43 & $t=-1.0027$ & 0.328 \\
\hline
\end{tabular}

data. We used a backward stepwise regression approach using the initial model,

$$
\begin{gathered}
y=\left(\beta_{1}+\theta_{1} \mathrm{~T}\right)+\left[\left(\beta_{2}+\theta_{2} \mathrm{~T}\right)-\left(\beta_{1}+\theta_{1} \mathrm{~T}\right)\right] \\
\left.\cdot \exp \left[-\exp \left(\beta_{3}+\theta_{3} \mathrm{~T}\right) x\right)\right]
\end{gathered}
$$

where $\beta_{1}$ is the asymptote parameter, $\beta_{2}$ is the $y$-intercept parameter, $\beta_{3}$ is the rate of increase parameter, $\mathrm{T}$ is an indicator variable, $\theta_{1}-\theta_{3}$ are indicator parameters, and $x$ is Chinook Salmon TL. Starting values were set to $\beta_{1}=175$, $\beta_{2}=-1,628$, and $\beta_{3}=-4.7$. Starting values for all $\theta$ parameters were set to 0 .

The least-significant of the nonsignificant $\theta$ parameters (i.e., those with $P>0.05$ ) were sequentially backward eliminated until all remaining parameters were significant. Each $\theta$ parameter represented a hypothesis test for differences between time periods in the associated $\beta$ parameter, where inclusion in the final model is equivalent to a rejection of the null hypothesis of no difference between time periods for that parameter. We set $\alpha=0.05$ for all of our statistical testing.

\section{Results}

Mean total weight of Chinook Salmon stomach contents and percentage of nonempty stomachs differed significantly between small angler-caught Chinook Salmon (3.40 g) and small survey-caught Chinook Salmon (0.98 g) in MM-6 and MM-8 Lake Michigan management units during 2009-2010 (Table 1). However, there was no difference in large Chinook Salmon mean total prey weight

Table 2. Binomial regression results for the presence of stomach contents as a function of Chinook Salmon TL and time

\begin{tabular}{|c|c|c|c|c|}
\hline Parameter & Estimate & SE & Z-value & $P$ \\
\hline Intercept & -2.907 & 0.1746 & -16.555 & $<0.001$ \\
\hline $\mathrm{TL}$ & 0.004 & 0.0002 & -14.563 & $<0.001$ \\
\hline Time period & 0.332 & 0.0845 & 3.928 & 0.089 \\
\hline \multicolumn{5}{|c|}{$\begin{array}{l}\text { Residual deviance: } 3,741 \\
\text { Degrees of freedom: } 2,740\end{array}$} \\
\hline
\end{tabular}
period. or percent empty stomachs between capture sources, and there was no significant difference in mean or maximum prey length per Chinook Salmon stomach between capture sources for either size-class. Because only minor differences in diets by capture source were observed, diets were combined and capture source was omitted from further analyses.

Binomial regression results indicated that there was a significant positive relationship between Chinook Salmon TL and the proportion of empty stomachs, but there was no significant difference in the percentage of empty stomachs between time periods (Table 2). Alewives comprised a majority of Chinook Salmon diet by weight across sizeclasses and time periods, from as low as $58 \%$ to as high as $99 \%$ (Figure 1). There was an increase in the percentage by weight $(\% W)$ of small and large Alewife prey between time periods in both Chinook Salmon size-classes (Table 3), though the increase was not significant for $\% W$ of large Alewife in small Chinook Salmon diets ( $t$-test: $P=$ 0.213). For large Chinook Salmon, the increase in importance of Alewife prey was offset by decreases in $\% W$ of Bloater and Rainbow Smelt from $14 \%$ to $<1 \%$ and from

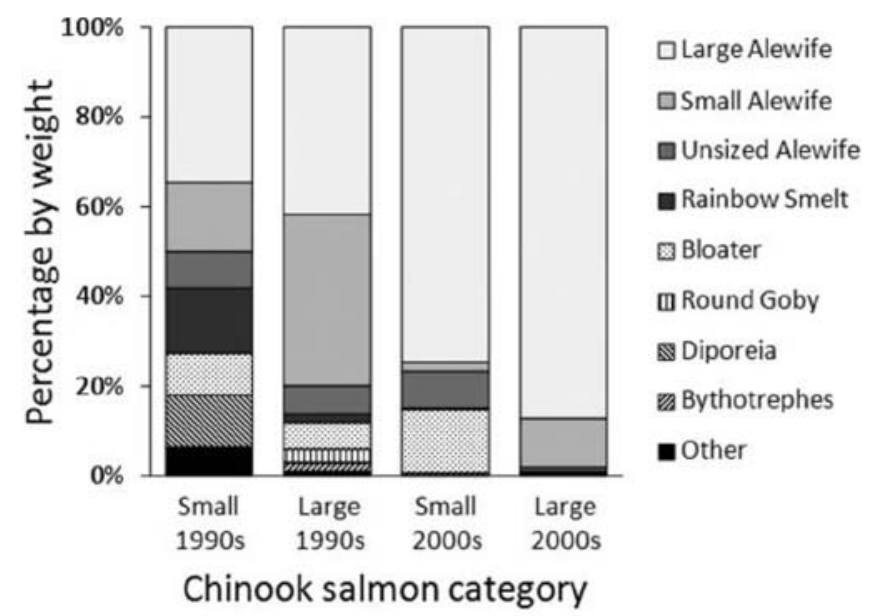

Figure 1. Percentage by weight of Chinook Salmon diet contents for each size-class (Small: <500 mm TL, Large: $\geq 500 \mathrm{~mm}$ TL) and time period (1990s: 1994-1996, 2000s: 2009-2010). 
Table 3. Diet contents for Chinook Salmon in each time period and size-class. $\% W$ denotes percentage diet by weight of prey items, $\% \mathrm{~N}$ denotes percentage diet by number of prey items, and $\% O$ denotes the percentage frequency of occurrence in predator stomachs by prey fish category.

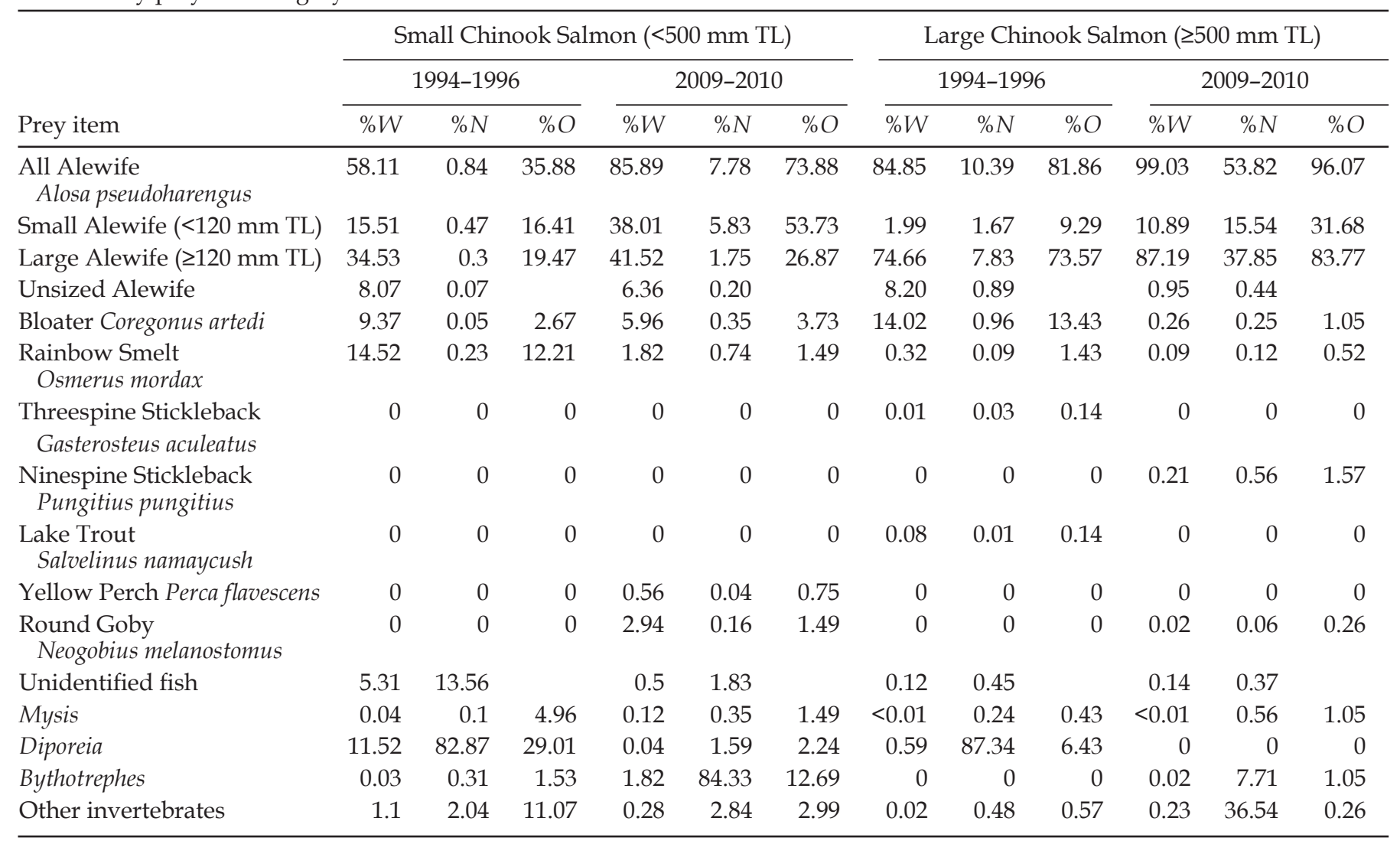

$15 \%$ to $2 \%$, respectively ( $t$-test: $P<0.001$ ), whereas for small Chinook Salmon there was a corresponding decrease in Diporeia \%W from $12 \%$ to $1 \%$ (t-test: $P<0.001)$. The invasion of the Round Goby in Lake Michigan, which occurred between our 1994- 1996 and 2009-2010 time periods (Madenjian et al. 2010), has had only a small impact on the diet of Chinook Salmon (Table 3). The most numerically important diet item in 1994-1996 for both Chinook Salmon size-classes was Diporiea. In 2009- 2010, Bythotrephes was the most numerically important diet item for small Chinook Salmon, and Alewife was the most numerically important diet item for large Chinook Salmon. Where Bythotrephes occurred in Chinook Salmon stomachs, it was often present in large numbers and with few or no other prey items, which would seem to indicate intentional, rather than incidental, ingestion.

Length-frequency distributions of Alewife prey showed that large Chinook Salmon preyed on a greater frequency of large Alewives than did small Chinook Salmon for both time periods (Figure 2). There was also a decrease in the relative frequency of large Alewife prey consumed from 1994-1996 to 2009-2010 periods in both predator size-classes. When compared with the distribution of 1994-1996 large Chinook Salmon, the distribution of Alewife prey TL for 2009-2010 large salmon was noticeably truncated.
Numerical density estimates for all major Chinook Salmon prey fish species were higher in 1994-1996 relative to 2009- 2010 (Figure 3). Alewives suffered the smallest decline in density between time periods. Interannual variation in the density estimates of small Alewives was high in both time periods, as evidenced by the large SE bounds. Round Gobies were not present in Lake Michigan prey fish surveys during 1994-1996, but estimated density of Round Gobies was similar to that of Rainbow Smelt and Bloaters during 2009-2010.

Chesson's selectivity index was greater than the critical value ( $C_{\text {crit }}$ ) for large Alewives in each combination of period, size-class, and prey assemblage (Figure 4). For large Chinook Salmon, large Alewife was the only prey species positively selected for $(C>C$ crit). For small Chinook Salmon in 1994-1996, there was avoidance of Bloaters and Rainbow Smelt and selection for small Alewives and large Alewives. For small Chinook Salmon in 20092010, large Alewives, small Alewives, and Rainbow Smelt were selected for, while Bloaters were avoided. When Round Goby was included in selection analysis for 20092010, Chesson's index changed only slightly for previous prey categories, the direction of prey selection (selection versus avoidance) for previous prey categories did not change, and Chesson's index for Round Goby indicated avoidance of this prey item. 

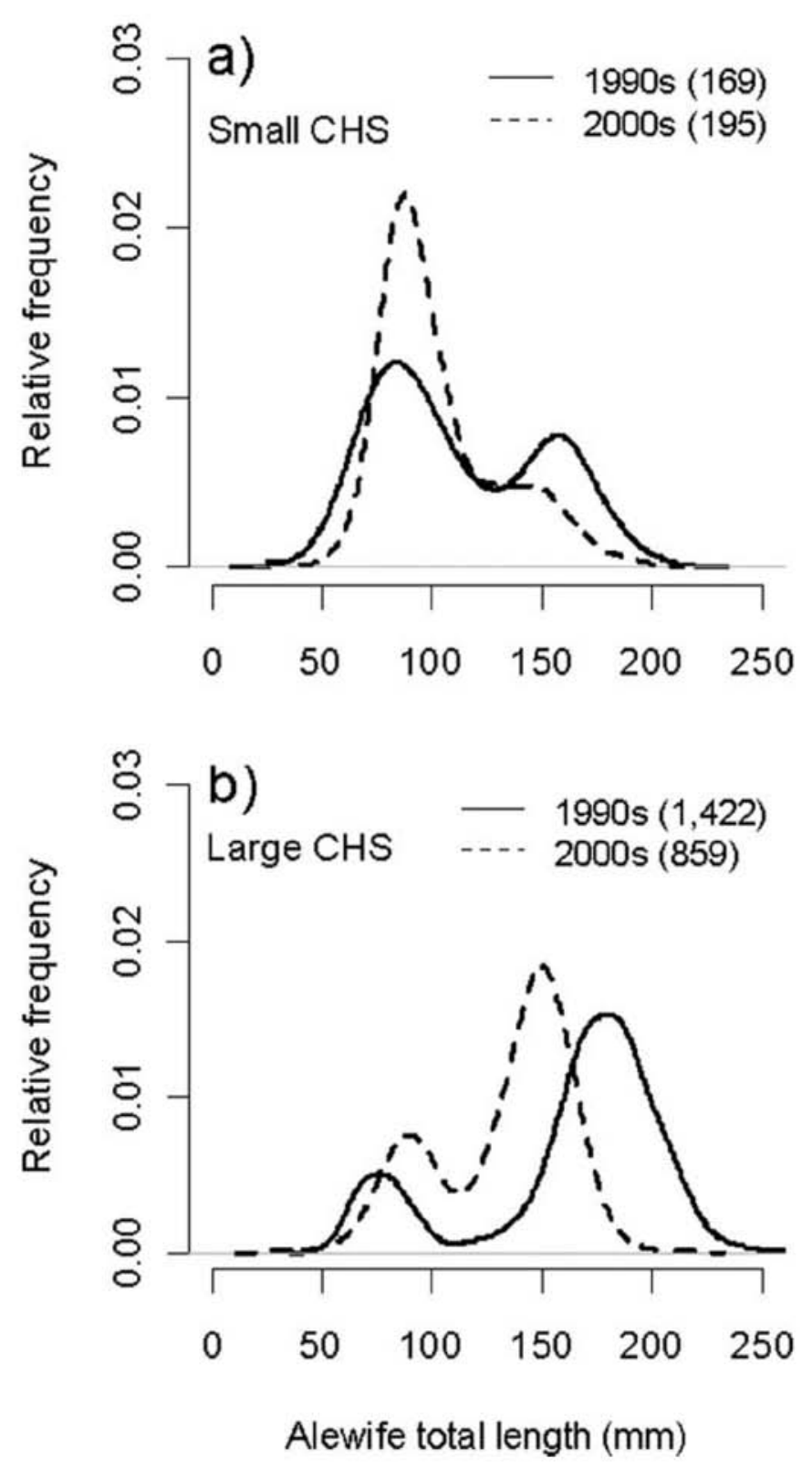

Figure 2. Proportional length-frequency distributions and associated sample sizes $(n)$ of (a) Alewife prey found in small Chinook Salmon (Small CHS; <500 mm TL) diets from both time periods (1990s: 1994-1996, 2000s: 2009- 2010), and (b) Alewife prey found in large Chinook Salmon (Large CHS; $\geq 500 \mathrm{~mm}$ TL) diets from both time periods. Lines are kernel density functions for all Alewives found in Chinook Salmon diets from each size and time period category.

Our final model for mean TL of Alewife prey per Chinook Salmon stomach as a function of salmon TL had significant asymptote, intercept, and rate of increase parameters, as well as significant indicator parameters for asymptote and rate of increase (Table 4). Significant indicator parameters for asymptote and rate of increase indicate statistically significant differences in their associated

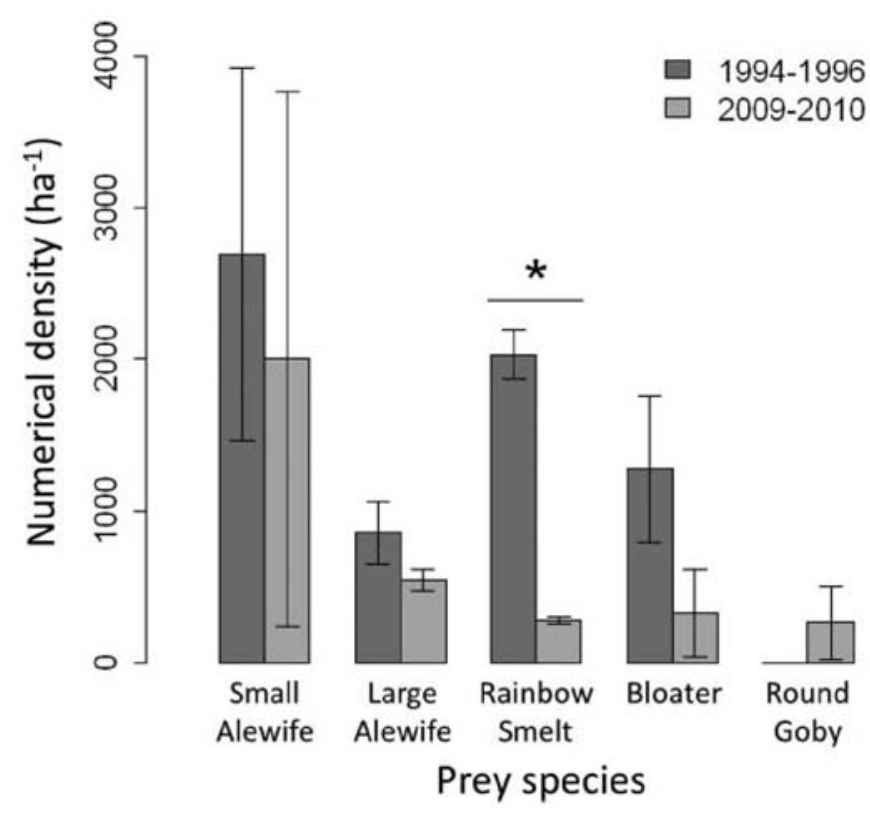

Figure 3. Mean $( \pm S E)$ of annual lake-wide Lake Michigan prey fish density estimates by time period. Significant differences between mean annual density estimates are denoted by an asterisk $\left(^{*}\right)(t$-test, $\alpha=0.05)$. Estimates for small Alewife, large Alewife, Rainbow Smelt, and Bloater are from U.S. Geological Survey (USGS) Lake Michigan acoustic prey fish surveys, and estimates for Round Goby are from USGS Lake Michigan bottom trawl surveys.

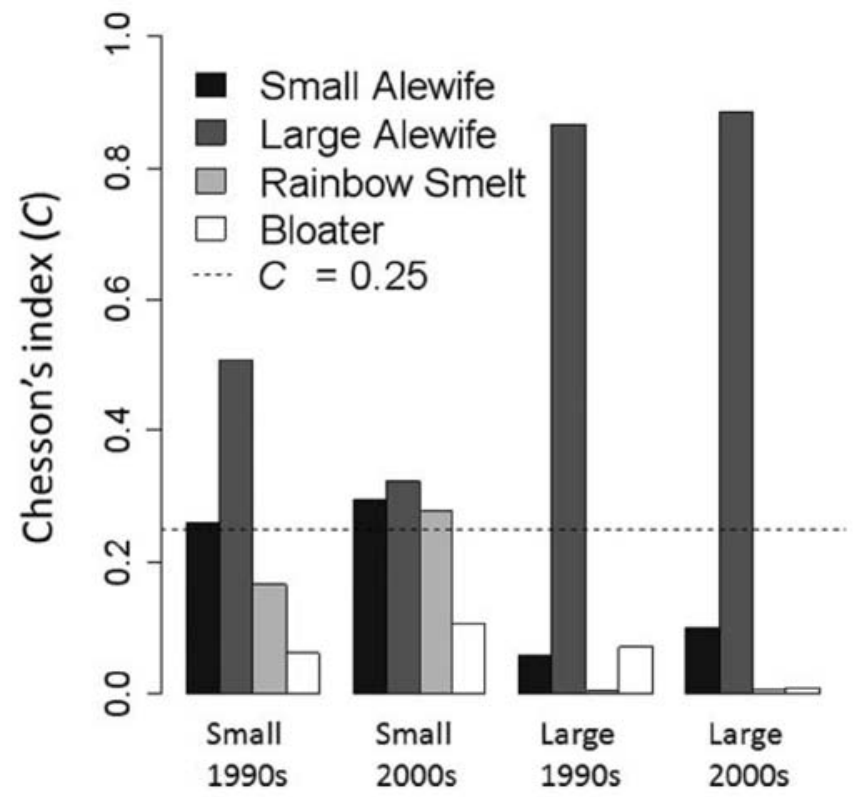

Figure 4. Chesson's index of selectivity for the four major prey categories - small Alewife, large Alewife, Rainbow Smelt, and Bloater - by Chinook Salmon size-class (Small: <500 mm TL, Large: $\geq 500 \mathrm{~mm}$ TL) and time period (1990s: 1994-1996, 2000s: 2009-2010). C corresponds to Chesson's selectivity index, and the horizontal dotted line corresponds to the critical $C$ value $\left(C_{\text {crit }}\right)$. Prey items are considered selected for when $C>C_{\text {crit }}$ and avoided when $C<C_{\text {crit }}$. 
Table 4. Final nonlinear regression model for the average TL of Alewife prey per predator stomach $\left(y_{i}\right)$ across Chinook salmon total length $\left(x_{i}\right)$, with an indicator variable $\left(\mathrm{T}_{i}\right)$ for time period. The $\beta_{1}$ parameter represents the asymptote, $\beta_{2}$ is the $y$ intercept parameter, $\beta_{3}$ is the rate of increase parameter, and $\theta_{1}-\theta_{3}$ are indicator parameters:

\begin{tabular}{lrrrr}
\multicolumn{4}{c}{$\left.y_{i}=\left(\beta_{1}+\theta_{1} \mathrm{~T}_{i}\right)+\left[\beta_{2}-\left(\beta_{1}+\theta_{1} \mathrm{~T}_{i}\right)\right] \cdot \exp \left[-\exp \left(\beta_{3}+\theta_{3} \mathrm{~T}_{i}\right) x_{i}\right)\right]$} \\
\hline Parameter & Start value & Estimate & $\mathrm{SE}$ & $P$ \\
\hline$\beta_{1}$ & 175 & 187.3 & 3.172 & $<0.001$ \\
$\beta_{2}$ & $-1,628$ & $-1,023$ & 349.4 & $<0.001$ \\
$\beta_{3}$ & -4.7 & -4.98 & 0.112 & $<0.001$ \\
$\theta_{1}$ & 0 & -49.07 & 3.225 & $<0.001$ \\
$\theta_{3}$ & 0 & 0.304 & 0.042 & $<0.001$
\end{tabular}

Residual SE: 27.93

Degrees of freedom: 1,088

$\beta$ parameters $\left(\beta_{1}\right.$ and $\beta_{3}$ ) between 1994-1996 and 20092010. The indicator parameter for intercept $\left(\theta_{2}\right)$ was nonsignificant and was removed during our selection procedure. This model shows that with increasing predator TL, Chinook Salmon from 1994 to 1996 selected larger Alewife prey at a slightly lower rate of increase, but to a greater asymptotic maximum than did 2009-2010 Chinook Salmon (Figure 5). There was little difference between periods at small predator size.

\section{Discussion}

With ongoing ecological change in the Great Lakes including a broad fish community shift in Lake Huron (Riley et al. 2008) and the decline of pelagic prey fish species in Lake Michigan (Madenjian et al. 2012), the outlook for Lake Michigan Chinook Salmon and Alewife populations (plus those of many other fishes) is somewhat uncertain, especially as Chinook Salmon have become increasingly dependent on Alewives. Our study results clearly reflect an increase in the importance of Alewives to Chinook Salmon diets in Lake Michigan from 1994-1996 to 2009-2010. Diet percentage for total Alewives by number, weight, and occurrence have all increased since the 1990s, though there has been a disproportionate increase in the importance of small Alewives as opposed to large Alewives. Additionally, selectivity for Alewife has remained significant for both size-classes of Chinook Salmon despite high variation and overall reduction in Alewife prey abundance. Though it has been well documented that Alewife is the primary forage species for Chinook Salmon in the Great Lakes (Jude et al. 1987; Stewart and Ibarra 1991; Rybicki and Clapp 1996; Warner et al. 2008), the increase in importance of this item to the further exclusion of other prey items has appeared to result in almost complete diet dependence on Alewife.

Previous studies have indicated that Chinook Salmon do not shift foraging habits in response to changes in the abundance of its preferred prey (Jude et al. 1987), though Chinook Salmon in Lake Michigan may change prey-size preference depending on the abundance of different size-

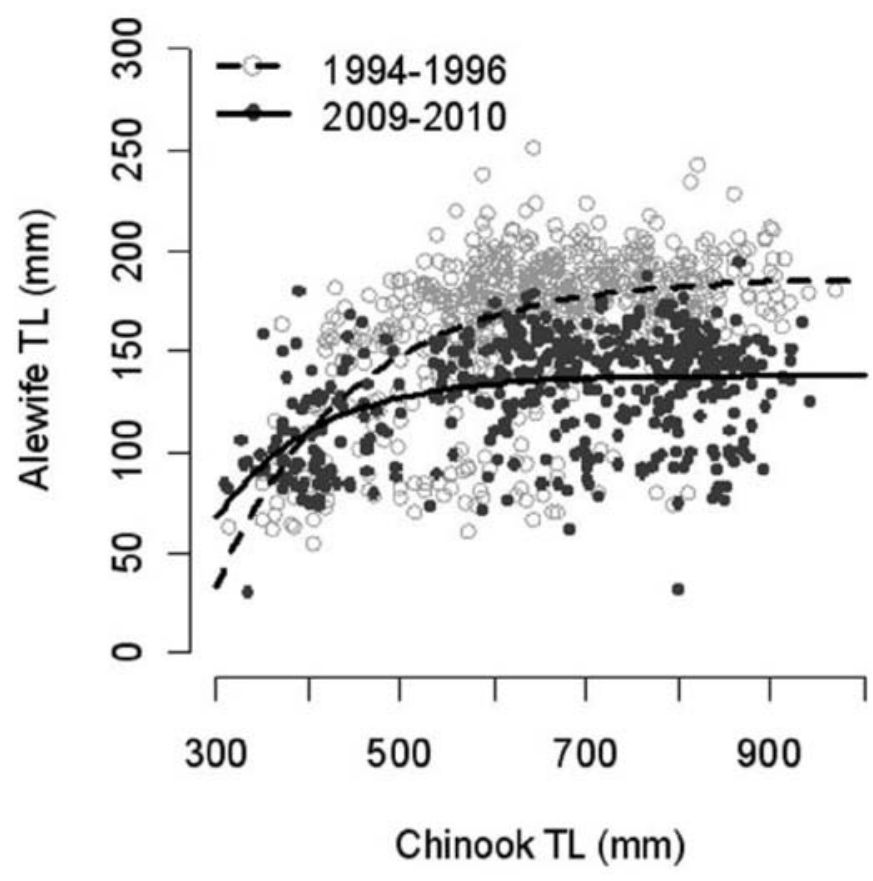

Figure 5. Plot of mean TL of Alewife prey found in each Chinook Salmon stomach versus Chinook Salmon TL. Regression lines represent predicted mean response derived from the asymptotic nonlinear relationship between Chinook Salmon TL and the mean TL of Alewives. Regression lines for each time period were plotted separately to illustrate the effect of the indicator variables for time period $\left(\theta_{1}\right.$ and $\left.\theta_{3}\right)$ from the final model (Table 4).

classes of Alewife prey (Warner et al. 2008). However, when we investigated Chinook Salmon prey selectivity between 1994-1996 and 2009-2010 time periods, there was little to no change in selectivity for either small or large Chinook Salmon. In small Chinook Salmon, there was positive selection for large and small Alewives during both time periods, though more detailed year-to-year analyses have generated more nuanced results with variation in annual Alewife abundance (Warner et al. 2008). Large Chinook Salmon exhibited strong, nearly exclusive, positive selection for large Alewives in both time periods, while all other prey species were avoided. Given the prey choices, we conclude that Chinook Salmon selectivity by species is inflexible to the extent and nature of ecological change that has occurred in Lake Michigan since 1994. Further, the consistently high preference for Alewife with increased diet dependence on Alewives may make Chinook Salmon more sensitive to changes in Alewife body size, condition, and abundance.

Selection solely for Alewife prey by Chinook Salmon, even when Alewife abundance was low, is supported by Jude et al. (1987) from evaluation of diets and prey levels between 1973 and 1982. However, Alewife abundance was lower in 1994-1996 and 2009-2010 when compared with abundance in 1973-1982, on average (Madenjian et al. 2012). Stewart and Ibarra (1991) investigated salmonine diet from 1978 to 1988 , a period that included the 1983-1985 span of very low adult Alewife abundance, 
mirroring the very low adult Alewife levels observed in Lake Michigan during 2004-2011 (Warner et al. 2011; Madenjian et al. 2012). Similar to our study, Stewart and Ibarra (1991) found that with decreasing Alewife abundance, there was an increase in the proportion of small Alewives consumed. However, Stewart and Ibarra (1991) found that there was a decrease in the proportion of large Alewives, and an increase in the proportion of other species in Chinook Salmon stomachs. Bottom trawl estimates of prey fish abundance during the 1980s showed that, although Alewife abundance was reduced compared with abundance during the 1970s, abundance of Bloaters and Rainbow Smelt remained relatively high (Madenjian et al. 2012). Though Rainbow Smelt and Bloater were by far the most available prey species during this time period, these species failed to dominate Chinook Salmon diet (Stewart and Ibarra 1991). Whereas Stewart and Ibarra (1991) found a modest degree of prey switching behavior by Chinook Salmon during the 1980s, when alternative prey were relatively abundant, we found no evidence of prey switching behavior by Chinook Salmon during the late 2000s, when alternative prey were low in abundance.

In Lake Michigan, several studies reported finding Alewife prey exceeding $200 \mathrm{~mm}$ TL in large salmonine diets during the mid-1990s (Rybicki and Clapp 1996; Madenjian et al. 1998a, 1998b; this study), but we know of no studies of salmonine diets in Lake Michigan that report finding such large Alewife prey during the late 2000s. For example, Savitz (2009) reported finding Alewives no larger than $178 \mathrm{~mm}$ TL in the diets of 713 anglercaught salmonines in southern Lake Michigan during 2001-2008. Though indicative of changes in the size distribution of Alewife prey in salmonine diets, these studies could not directly compare diet habits between time periods, as ours did. For large Chinook Salmon in our study, the length-frequency distribution of Alewife prey was truncated in 2009-2010 compared with that of 1994-1996. Small Chinook Salmon in 2009-2010 preyed on a higher frequency of small Alewives than did small Chinook Salmon in 1994-1996, shown in Figure 2 as a difference in peak height for Alewife $<120$ mm TL. Similarly, our nonlinear regression analysis of average Alewife TL versus predator TL indicated that the asymptotic mean Alewife size consumed by the largest Chinook Salmon was $49 \mathrm{~mm}$ shorter in 2009-2010 than in 1994-1996. This result seems to mirror the differences in maximum prey sizes reported by diet studies in the 1990s versus the 2000s (Rybicki and Clapp 1996; Madenjian et al. 1998a, 1998b; Savitz 2009) and certainly parallels changes in Alewife size and abundance found in prey fish surveys between these time periods (Warner et al. 2011; Madenjian et al. 2012).

Lake Michigan Alewives experienced decreases in growth, condition, and energy density in the late 1990s, and these decreases were attributed to the decline in $\mathrm{Di}$ poreia abundance (Madenjian et al. 2003, 2006; Nalepa et al. 2006). Through bioenergetics modeling, Madenjian et al. (2006) found that these declines could increase consumptive demand for Chinook Salmon, increasing the amount of Alewife prey necessary to attain expected growth rates by over $20 \%$. Herein, we find that during 2009-2010, Chinook Salmon (1) consumed higher percentages of Alewives than in the 1990s and (2) consumed significantly smaller-sized Alewives than in the 1990s. From a bioenergetics perspective, the possibility that Chinook Salmon in the late 2000s were eating smaller-sized Alewives nearly exclusively could mean increases in search and handling time on a per prey-item basis and decreasing overall foraging efficiency. Even though it may be difficult to quantify changes in foraging efficiency with decreases in prey size and condition, any such reduction in prey size would be expected to further increase Chinook Salmon consumption demand beyond that suggested by Madenjian et al. (2006). From an Alewife population dynamics perspective, although Alewives have periodically produced large year-classes that disproportionately contribute to lake-wide biomass (Warner et al. 2011), decreasing abundance of large Alewives amid increasing Alewife predation may eventually decrease reproductive capacity to the point of recruitment depensation.

An additional source of consumptive demand for Alewife could derive from Chinook Salmon migrating from Lake Huron. Adlerstein et al. (2007) found that $6 \%$ of coded-wire-tagged Chinook Salmon from Lake $\mathrm{Hu}-$ ron were recovered in Lake Michigan during 1993-2001, whereas Adlerstein et al. (2008) found no evidence of Lake Michigan Chinook Salmon recoveries in Lake Huron. Since wild Chinook Salmon production has remained high after the Alewife population collapse that occurred in Lake Huron soon thereafter (Johnson et al. 2010), there is some concern that substantial numbers of Chinook Salmon are crossing the Straits of Mackinac into Lake Michigan to forage. Wild reproduction of Chinook Salmon also occurs in Lake Michigan, and though highly variable, in some years it has exceeded stocking levels (Claramunt et al. 2010). If the influx of wild fish into Lake Michigan is large enough, overall salmonine abundance and forage requirements could increase (1) beyond that intended by fisheries management agency stocking practices and (2) beyond the ability of the prey base to support them. This hypothetical situation mirrors one implied by Roseman and Riley (2009) and Riley et al. (2008) to be a contributing factor in Lake Huron's community collapse: increasing salmonine predator abundance and consumption amid a declining prey base.

Bottom-up trophic dynamics in Lake Michigan can be expected to exert pressure on top predators like Chinook Salmon chiefly though prey fish populations like Alewives, Bloaters, or Rainbow Smelt (Warner et al. 2008). However, our results indicate that smaller Chinook Salmon could be more directly affected by shifting benthic invertebrate and zooplankton community structure. Among other differences in diet composition between time periods, we found that in small Chinook Salmon, there was a striking decrease in all three metrics of diet importance for Diporeia and an increase for Bythotrephes, possibly in response to reduced Diporeia abundance in 
Lake Michigan (Nalepa et al. 2006). Though Bythotrephes did not represent a particularly high percentage of small Chinook Salmon diet by weight in 2009-2010 (1.82\%W), this species was found in over $12 \%$ of small Chinook Salmon diets and represented $84 \%$ of diet items by number. Comparatively, Bythotrephes was found in $<2 \%$ of small Chinook Salmon diets and represented $<1 \%$ of diet content by number and weight in 1994-1996. Diporeia consumption in 1994-1996 represented over 11\% of small Chinook Salmon diet by weight and over $82 \%$ by number, whereas in 2009-2010 these numbers had declined to $<1 \% W$ and $1.6 \% \mathrm{~N}$. There was also a significant reduction in percentage by number and by occurrence of Diporeia in large Chinook Salmon from the 1990s (when Diporeia represented $87 \% \mathrm{~N}$ and $6 \% \mathrm{O}$ ) to the 2000s (when there was no evidence of Diporeia consumption). Madenjian et al. (1998b) found that significant proportions (by weight) of coho salmon O. kisutch diets were made up of Bythotrephes and benthic invertebrates in 1994 and 1995. So, there is evidence that salmonines exploit prey items from lower trophic levels, like Diporeia and Bythotrephes, but the importance of this aspect of Chinook Salmon feeding ecology remains untested.

Though the decline in prey fish abundance was significant only for Rainbow Smelt between our 1994-1996 and 2009-2010 time periods (Figure 3), declines in all three prey species are quite significant when broader prey survey results are considered. Results from both bottom trawl and acoustic surveys indicated that abundance of large Alewives, Rainbow Smelt, and Bloaters in Lake Michigan underwent substantial decline between the mid-1990s and the late 2000s (Warner et al. 2011; Madenjian et al. 2012). Specifically, both surveys documented a roughly $40 \%$ decrease in large Alewife abundance between the two time periods, and a decrease in the abundance of Rainbow Smelt and Bloaters by more than a factor of three. Decreases for all three prey species between the 1993-1996 and 2005-2010 time periods, which were only slightly broader, were statistically significant (Madenjian et al. 2012).

Coupling our findings with results from several recent studies, we conclude that the relatively low abundance of Alewives in Lake Michigan during the late 2000s was most probably due to increased predation by Chinook Salmon brought about by (1) increased importance of Alewives in the diet of Chinook Salmon, (2) reduced condition, growth, and energy density of Alewives during the 2000s, and (3) activation of new sources of Chinook Salmon wild recruitment to Lake Michigan during the late 1990s or early 2000s. Our results show that the importance of Alewives in Chinook Salmon diet increased between the 1994-1996 and 2009-2010 periods. In addition, we demonstrated that the proportion of small Alewives in the diet of Chinook Salmon increased between the two time periods. A sufficiently large increase in mortality of younger Alewives, while maintaining a high rate of predation mortality for older Alewives, would be expected to shorten the longevity of Alewives in Lake Michigan.
Coincidentally, the age distribution of Alewives from prey fish surveys in Lake Michigan during 2009-2010 was truncated compared with the Alewife age distribution during the mid-1990s (Madenjian et al. 2012), thereby indicating that the longevity of Alewives between these two time periods has indeed decreased. Nearly all of the Lake Michigan Alewives with TL $<100 \mathrm{~mm}$ caught in bottom trawls or midwater trawls during the late 2000s were either age- 0 or age- 1 fish (Warner et al. 2011; Madenjian et al. 2012), and this age composition of the smaller Alewives during the late 2000s was apparently similar to that during the 1970s (Stewart and Binkowski 1986). Thus, increased importance of smaller, and presumably younger, Alewives may lead to increased predation mortality for younger Alewives. As previously mentioned, the decrease in Lake Michigan Alewife energy density, which probably occurred during the mid or late 1990s, could potentially lead to a substantial increase in the rate of Alewife consumption by Chinook Salmon (Madenjian et al. 2006). Finally, the surge in production of wild Chinook Salmon smolts originating from one tributary or set of tributaries to Georgian Bay of Lake Huron during the late 1990s or early 2000s, as documented by Johnson et al. (2010) and Marklevitz et al. (2011), may have led to a substantial increase in Chinook Salmon abundance in Lake Michigan between the 1994-1996 and 2009-2010 periods.

Alewife abundance in Lake Michigan has been primarily driven by predation by salmonines (Madenjian et al. 2002, 2005; this study), whereas the condition and growth of Alewives in Lake Michigan has been strongly influenced by Diporeia abundance (Madenjian et al. 2003, 2006). We suggest that recent changes in the abundance, age structure, and size structure of the Alewife population in Lake Michigan are the combined result of these respective top-down and bottom-up forces. Specifically, the reduction in Alewife growth and condition brought about by the decrease in Diporeia abundance has probably further exacerbated the effect of salmonine predation, leading to reduced abundance, especially of large-sized Alewives. In contrast to Alewives, strong links between salmonine predation and the abundance of Bloaters and Rainbow Smelt in Lake Michigan have yet to be established (Madenjian et al. 2002). Considerably more research will be needed to fully quantify the mechanisms by which bottom-up forcing may affect the abundance of prey fish species other than Alewife. To fully assess these bottom-up effects on prey fish biomass in Lake Michigan, additional years of surveillance, across-lake comparisons, and food-web analyses will be needed (Madenjian et al. 2012).

Sweeping ecosystem and community changes have occurred in the Great Lakes since the 1990s (Barbiero and Tuchman 2004; Bunnell et al. 2006). In Lake Huron, changes in fish community composition may be associated with a recent resurgence of native populations of fishes such as Lake Trout Salvelinus namaycush, Walleye Sander vitreus, and Emerald Shiner Notropis atherinoides (Schaeffer et al. 2008; Riley et al. 2010). Due to the role of Chinook Salmon as a top predator and the management 
interest in maintaining a recreational Chinook Salmon fishery (Eshenroder et al. 1995), an understanding of trophic interactions between Chinook Salmon and their prey is necessary to (1) determine how ecosystem and community change in Lake Michigan may affect Chinook Salmon and their prey, and (2) inform effective multispecies management practices in Lake Michigan, should it be for maintenance of the largely alewife-dependent Pacific salmonine populations, for rehabilitation of native fish species, or for both. Unlike Lake Huron, Lake Michigan has benefited from fishery-dependent and fishery-independent Pacific salmonine monitoring that has included diet collections, though considerably more survey effort has focused on species at lower trophic levels (e.g., Warner et al. 2011; Madenjian et al. 2012) or on native fish rehabilitation (Holey et al. 1995). Without these data on Pacific salmonines, the role of top predators in the Lake Michigan ecosystem may be difficult to evaluate. In particular, more work is needed to illuminate within-year and within-lake changes in habitat use, prey distribution, and predator-prey dynamics in the context of ongoing ecosystem change. However, with continued rigorous assessment of top-predator populations, foraging habits similar to those reported herein can be used to quantify ecological links between top predators and their prey and may help quantify community-level responses to ecosystem and community change in Lake Michigan.

Acknowledgments - The authors thank Scott Hansen, Brad Eggold, and the Wisconsin Department of Natural Resources (DNR); Brian Breidert and the Indiana DNR; Steve Robillard and the Illinois DNR; and Jay Wesley and the MDNR for providing Chinook Salmon stomachs from fishing tournaments and fishery-independent gill-net surveys. We thank Marty Williams for helping coordinate Chinook Salmon collections and for biological data management. Jeff Holuszko and Emily Haug helped conduct diet analyses. We appreciate the contribution of the MDNR vessel crew members and researchers including Jerry Ranville, James Harris, Eric Crissman, Bryce Kucharek, and Brian Flood. Jean Adams assisted with statistical analyses. Mention of specific products does not constitute endorsement by the U.S. Government or the MDNR. This article is Contribution 1712 of the U.S. Geological Survey Great Lakes Science Center.

\section{References}

Adlerstein, S. A., E. S. Rutherford, D. Clapp, J. A. Clevenger, and J. E. Johnson. 2007. Estimating seasonal movements of Chinook Salmon in Lake Huron from efficiency analysis of coded wire tag recoveries in recreational fisheries. North American Journal of Fisheries Management 27:792-803.

Adlerstein, S. A., E. S. Rutherford, R. M. Claramunt, D. F. Clapp, and J. A. Clevenger. 2008. Seasonal movements of Chinook Salmon in Lake Michigan based on tag recoveries from recreational fisheries and catch rates in gill-net assessments. Transactions of the American Fisheries Society 137:736-750.
Argyle, R. L., G. W. Fleischer, G. L. Curtis, J. V. Adams, and R. G. Stickel. 1998. An integrated acoustic and trawl-based prey fish assessment strategy for Lake Michigan. Report to the Illinois Department of Natural Resources, Indiana Department of Natural Resources, Michigan Department of Natural Resources, and Wisconsin Department of Natural Resources. U.S. Geological Survey, Biological Resources Division, Great Lakes Science Center, Ann Arbor, Michigan.

Barbiero, R. P., M. Balcer, D. C. Rockwell, and M. L. Tuchman. 2009. Recent shifts in the crustacean zooplankton community of Lake Huron. Canadian Journal of Fisheries and Aquatic Sciences 66:816-828.

Barbiero, R. P., and M. L. Tuchman. 2004. Changes in the crustacean communities of Lakes Michigan, Huron, and Erie following the invasion of the predatory cladoceran $B y$ thotrephes longimanus. Canadian Journal of Fisheries and Aquatic Sciences 61:2111-2125.

Bunnell, D. B., S. R. David, and C. P. Madenjian. 2009. Decline in Bloater fecundity in southern Lake Michigan after decline of Diporeia. Journal of Great Lakes Research 35:45-49.

Bunnell, D. B., C. P. Madenjian, and R. M. Claramunt. 2006. Long-term changes of the Lake Michigan fish community following the reduction of exotic Alewife (Alosa pseudoharengus). Canadian Journal of Fisheries and Aquatic Sciences 63:2434-2446.

Chesson, J. 1978. Measuring preference in selective predation. Ecology 59: 211-215.

Claramunt, R. M., B. Breidert, D. F. Clapp, R. F. Elliott, S. P. Hansen, C. P. Madenjian, P. Peeters, S. R. Robillard, D. M. Warner, and G. Wright. 2010. Status of Lake Michigan salmonines in 2009: a report from the salmonid working group. Great Lakes Fishery Commission, Lake Michigan Committee, draft report, Ann Arbor, Michigan.

Depew, D. C., S. J. Guildford, and R. E. H. Smith. 2006. Nearshore-offshore comparison of chlorophyll $a$ and phytoplankton production in the dreissenid-colonized eastern basin of Lake Erie. Canadian Journal of Fisheries and Aquatic Sciences 63:1115-1129.

Elliott, R. F., P. J. Peeters, M. P. Ebener, R. W. Rybicki, P. J. Schneeberger, R. J. Hess, J. T. Francis, G. W. Eck, and C. P. Madenjian. 1996. Conducting diet studies of Lake Michigan piscivores: a protocol. U.S. Fish and Wildlife Service, Report 96-3, Ann Arbor, Michigan.

Eshenroder, R. L., M. E. Holey, T. K. Gorenflo, and R. D. Clark Jr. 1995. Fish community objectives for Lake Michigan. Great Lakes Fishery Commission, Special Publication 95-3, Ann Arbor, Michigan.

Hecky, R. E., R. E. H. Smith, D. R. Barton, S. J. Guildford, W. D. Taylor, M. N. Charlton, and T. Howell. 2004. The nearshore phosphorus shunt: a consequence of ecosystem engineering by dreissenids in the Laurentian Great Lakes. Canadian Journal of Fisheries and Aquatic Sciences 61:1285-1293.

Holey, M. E., R. W. Rybicki, G. W. Eck, E. H. Brown Jr., J. E. Marsden, D. S. Lavis, M. L. Toneys, T. N. Trudeau, and R. M. Horrall. 1995. Progress toward Lake Trout restoration in Lake Michigan. Journal of Great Lakes Research 21(Supplement 1):128-151.

Hunt, S. L., T. J. Mulligan, and K. Komori. 1999. Oceanic feeding habits of Chinook Salmon, Oncorhynchus tshawytscha, off northern California. U.S. National Marine Fisheries Service Fishery Bulletin 97:717-721. 
Johnson, J. E., S. P. DeWitt, and D. J. A. Gonder. 2010. Massmarking reveals emerging self regulation of the Chinook Salmon population in Lake Huron. North American Journal of Fisheries Management 30:518-529.

Jones, M. L., J. F. Koonce, and R. O'Gorman. 1993. Sustainability of hatchery-dependent salmonine fisheries in Lake Ontario: the conflict between predator demand and prey supply. Transactions of the American Fisheries Society 122:1002-1018.

Jude, D. J., F. J. Tesar, S. F. Deboe, and T. J. Miller. 1987. Diet and selection of major prey species by Lake Michigan salmonines, 1973-1982. Transactions of the American Fisheries Society 116:677-691.

Lauer, T. E., P. J. Allen, and T. S. McComish. 2004. Changes in mottled sculpin and Johnny Darter trawl catches after the appearance of Round Gobies in the Indiana waters of Lake Michigan. Transactions of the American Fisheries Society 133:185-189.

Madenjian, C. P., D. B. Bunnell, T. J. Desorcie, M. A. Chriscinske, M. J. Kostich, and J. V. Adams. 2012. Status and trends of prey fish populations in Lake Michigan, 2011. Great Lakes Fishery Commission, Lake Michigan Committee, Ann Arbor, Michigan.

Madenjian, C. P., T. J. Desorcie, and R. M. Stedman. 1998a. Ontogenic and spatial patterns in diet and growth of Lake Trout in Lake Michigan. Transactions of the American Fisheries Society 127:236-252.

Madenjian, C. P., R. F. Elliott, L. J. Schmidt, T. J. Desorcie, R. J. Hesselberg, R. T. Quintal, L. J. Begnoche, P. M. Bouchard, and M. E. Holey. 1998b. Net trophic transfer efficiency of PCBs to Lake Michigan Coho Salmon from their prey. Environmental Science and Technology 32:3063-3067.

Madenjian, C. P., G. L. Fahnenstiel, T. H. Johengen, T. F. Nalepa, H. A. Vanderploeg, G. W. Fleischer, P. J. Schneeberger, D. M. Benjamin, E. B. Smith, J. R. Bence, E. S. Rutherford, D. S. Lavis, D. M. Robertson, D. J. Jude, and M. P. Ebener. 2002. Dynamics of the Lake Michigan food web, 1970-2000. Canadian Journal of Fisheries and Aquatic Sciences 59: 736-753.

Madenjian, C. P., J. D. Holuszko, and T. J. Desorcie. 2003. Growth and condition of Alewives in Lake Michigan, 1984-2001. Transactions of the American Fisheries Society 132:1104-1116.

Madenjian, C. P., T. O. Höök, E. S. Rutherford, D. M. Mason, T. E. Croley II, E. B. Szalai, and J. R. Bence. 2005. Recruitment variability of Alewives in Lake Michigan. Transactions of the American Fisheries Society 134:218- 230.

Madenjian, C. P., S. A. Pothoven, J. M. Dettmers, and J. D. Holuszko. 2006. Changes in seasonal energy dynamics of Alewife (Alosa pseudoharengus) in Lake Michigan after invasion of dreissenid mussels. Canadian Journal of Fisheries and Aquatic Sciences 63:891-902.

Marklevitz, S. A. C., B. J. Fryer, D. Gonder, Z. Yang, J. Johnson, A. Moerke, and Y. E. Morbey. 2011. Use of otolith chemistry to discriminate juvenile Chinook Salmon (Oncorhynchus tshawytscha) from different wild populations and hatcheries in Lake Huron. Journal of Great Lakes Research 37: 698-706.

Nalepa, T. F., D. L. Fanslow, A. J. Foley III, G. A. Lang, B. J. Eadie, and M. A. Quigley. 2006. Continued disappearance of the benthic amphipod Diporeia spp. in Lake Michigan: is there evidence for food limitation? Canadian Journal of Fisheries and Aquatic Sciences 63:872-890.
Rennie, M. D., W. G. Sprules, and T. B. Johnson. 2009. Factors affecting the growth and condition of Lake Whitefish (Coregonus clupeaformis). Canadian Journal of Fisheries and Aquatic Sciences 66:2096-2108.

Riley, S. C., E. F. Roseman, J. V. Adams, T. P. O'Brien, and S. A. Farha. 2010. Status and trends of the Lake Huron offshore demersal fish community, 1976-2009. Great Lakes Fishery Commission, Lake Michigan Committee, Ann Arbor, Michigan.

Riley, S. C., E. F. Roseman, S. J. Nichols, T. P. O'Brien, C. S. Kiley, and J. S. Schaeffer. 2008. Deepwater demersal fish community collapse in Lake Huron. Transactions of the American Fisheries Society 137:1879-1890.

Roseman, E. F., and S. C. Riley. 2009. Biomass of deepwater demersal forage fishes in Lake Huron, 1994-2007: implications for offshore predators. Aquatic Ecosystem Health and Management 12:29-36.

Rybicki, R. W., and D. F. Clapp. 1996. Diet of Chinook Salmon in eastern Lake Michigan, 1991-93. Michigan Department of Natural Resources, Fisheries Research Report 2027, Ann Arbor.

Savitz, J. 2009. Diets of Lake Michigan salmon and maximum size of Alewife prey. Journal of Freshwater Ecology 24:563-566.

Schaeffer, J. S., D. M. Warner, and T. P. O'Brien. 2008. Resurgence of Emerald Shiners Notropis atherinoides in Lake Huron's main basin. Journal of Great Lakes Research 34:395-403.

Schneeberger, P., M. Toneys, R. Elliott, J. Jonas, D. Clapp, R. Hess, and D. Passino-Reader. 2001. Lakewide assessment plan for Lake Michigan fish communities. Great Lakes Fishery Commission, Special Report 1-64, Ann Arbor, Michigan.

Stewart, D. J., and F. P. Binkowski. 1986. Dynamics of consumption and food conversion by Lake Michigan Alewives: an energetics-modeling synthesis. Transactions of the American Fisheries Society 115:643-661.

Stewart, D. J., and M. Ibarra. 1991. Predation and production by salmonine fishes in Lake Michigan, 1978-88. Canadian Journal of Fisheries and Aquatic Sciences 48:909-922.

Stewart, D. J., J. F. Kitchell, and L. B. Crowder. 1981. Forage fishes and their salmonid predators in Lake Michigan. Transactions of the American Fisheries Society 110:751-763.

Szalai, E. B., J. R. Bence, and C. P. Madenjian. 2008. Quantifying the effects of salmonine predation on Alewife (Alosa pseudoharengus) and Bloater (Coregonus hoyi) population dynamics in Lake Michigan, 1962-1999. Quantitative Fisheries Center, Michigan State University, Technical Report T2008-06, East Lansing.

Tody, W. H., and H. A. Tanner. 1966. Coho Salmon for the Great Lakes. Michigan Department of Natural Resources, Fisheries Division, Fish Management Report 1, Lansing.

Warner, D. M., R. M. Claramunt, and J. D. Holuszko. 2011. Status of pelagic prey fishes and pelagic macroinvertebrates in Lake Michigan, 2010. Great Lakes Fishery Commission, Lake Michigan Committee, Ann Arbor, Michigan.

Warner, D. M., C. S. Kiley, R. M. Claramunt, and D. F. Clapp. 2008. The influence of Alewife year-class strength on prey selection and abundance of age-1 Chinook Salmon in Lake Michigan. Transactions of the American Fisheries Society 137:1683-1700. 